\title{
Effect of Medical Student Contributions on Academic Productivity: Analysis of Student Authorship Over Time
}

\author{
Carolyn K Kan' \\ Muhammad M Qureshi' \\ Munizay Paracha ${ }^{2}$ \\ Teviah E Sachs ${ }^{3}$ \\ Suzanne Sarfaty ${ }^{2}$ \\ Ariel E Hirsch ${ }^{1}$ \\ 'Department of Radiation Oncology, \\ Boston Medical Center, Boston, MA, \\ USA; ${ }^{2}$ Department of Medicine, Boston \\ Medical Center, Boston, MA, USA; \\ ${ }^{3}$ Department of Surgical Oncology, \\ Boston Medical Center, Boston, MA, USA
}

Correspondence: Ariel E Hirsch Department of Radiation Oncology, Boston Medical Center, Moakley Building, Lower Level, 830 Harrison Avenue,

Boston, MA, 02118, USA

Tel + I 617-638-7070

Email Ariel.Hirsch@bmc.org
Introduction: Understanding the trend of student authorship is crucial in determining its correlation to scholarly impact for corresponding authors. Our objective is to investigate student authorship rates over time in articles published in JAMA Internal Medicine (IM), as well as to examine potential effects student authors have on scholarly impact scores of corresponding authors via $\mathrm{H}$-index measures.

Methods: Authorship data including student authors (SA), first student authors, and corresponding authors (CA) from prior JAMA IM publications between 2010 and 2018 were collected, with a total of 701 studies. Analysis of variance (ANOVA) and independent sample $t$-tests were performed to assess for differences in the mean by publishing year and student authorship, respectively.

Results: Of 4591 total authors, 683 (14.9\%) were considered student authors. The percentage of student authorship increased from 46.3\% to 58.0\% between 2010 and 2018, respectively. No difference in average $\mathrm{H}$-indices of CA between SA and non-SA groups (overall NSA $H_{i}$ mean: 30.2 , vs $S A H_{i}$ mean: $32.1, p=0.371$ ) was noted.

Discussion: Student participation in research is not a disadvantage to scholarly impact for corresponding authors. Increased student authorship reflects a promising trend towards greater student participation in research within the field of medicine.

Keywords: student research, medical student, academic productivity, H-index, authorship

\section{Introduction}

Research remains an integral component for academic medical professionals, as scholarly productivity is frequently used as a consideration for faculty promotion. $^{1-3}$ Its importance and impact on clinical care management have also trickled down into medical education. Given that research participation has been shown to develop critical skills for post-graduate success, many medical schools now offer research electives to promote scholarly pursuits. ${ }^{4-9}$ As the overall demand for residency programs continues to increase, extracurricular activities, including research, have become encouraged in bolstering applicants' overall competitiveness for the National Resident Matching Program (NRMP). ${ }^{10,11}$ In 2018, approximately $78.0 \%$ of students reported during research during medical school according to NRMP Charting Outcomes, of which students published an average of 5.8 publications across all specialty applications. ${ }^{12}$ This is compared to 2009 , where these same reports showed an average of 2.2 publications. ${ }^{13}$ 
From a medical student perspective, students also gain valuable experiences from research involvement. Previous work had noted stronger student-faculty relationships, more reformed academic skills as critical thinking and review, increased productivity, and long-term mentorship for students pursuing research compared to their counterparts. ${ }^{14-18}$

Despite these benefits, students have noted multiple obstacles in undertaking research projects. For example, time constraints during medical school can pose challenges in designing and implementing research proposals from start to finish. ${ }^{19-21}$ Others reported coordination difficulties from mentors due to increasing demands on clinician educators for concurrent roles. ${ }^{15,21,22}$ Inherent difficulties in research completion - including IRB approval, patient consent process, as well as data collection and analyses - can also contribute to the challenges of performing research in general. ${ }^{20}$

Since its development in 2005, the H-index $\left(\mathrm{H}_{\mathrm{i}}\right)$ has been widely utilized as a biometric indicator in evaluating research productivity. ${ }^{23,24}$ As a parameter to quantify individuals' scientific output and scholarly impact in a given year, it can be applied to any set of papers, journals, counties, and even within specific fields. ${ }^{25-30}$ For our purposes, the H-index can also be used to assess the impact of student authorship on published research as a quantitative measure of author productivity.

To date, studies examining student authorship and mentorship in medical research are limited. There have been previous studies examining specific career fields, for instance, surgical specialties and radiation oncology, though no papers have looked at broader career fields as indicators of more generalized student trends. ${ }^{31,32}$ Given the size and breadth of internal medicine as a field, this will offer insight into the underlying changes of student authorship on scholarly impact for a large cohort population.

Here our objectives are two-fold: first, to analyze student authorship rates over time in the Journal of the American Medical Association (JAMA) Internal Medicine, and second, to examine the effects student authors have on the scholarly impact of corresponding authors (CA) in a major medical journal over time utilizing $\mathrm{H}$-index scores.

\section{Methods}

All authors from articles published in the Journal of the American Medical Association Internal Medicine (JAMA
IM) during the years of 2010, 2014, and 2018 were identified and ascribed into a compiled database. Each author's degree was recorded, with designations assigned as either corresponding author (CA), student author (SA), or other author. Other data points were documented: number of total authors, SA placement(s), SA degree(s), type of published article, CA's geographic location, as well as CA's H-score. The student author was defined as an author with a non-doctoral, non-medical degree; for example, NPs, RNs, authors with bachelor degrees, master's degrees, and Ph.D. candidates were considered student authors. Student authors who were also first authors (FA) were especially noted during data collection to assist in subsequent subset analyses. Inclusion criteria for journal articles included: original investigations, systematic reviews, evidence to practice, research letters, teaching moments, case report/case series, clinical observation, and special communication articles.

For each of the sampled years, $\mathrm{H}_{\mathrm{i}}$ scores were identified for $\mathrm{CA}$ at the time of publication of the article, as determined by Scopus. ${ }^{33}$ For CA, who had publications in multiple years, all $\mathrm{H}_{\mathrm{i}}$ were tabulated over time. Published articles were divided into two groups: articles with SA and those without student authors (nSA). CA, with multiple publications within the same year, were only counted once and designated as having student authors if at least one of their publications had a SA. All data were collected from September 2019 to February 2020.

Descriptive statistics were computed to describe the study cohort. Results are expressed as mean (standard deviation), median (interquartile range), and number (column percent). Geographic classifications within the United States (US) followed standard region stratifications (Northeast, Midwest, South, West). Analysis of variance (ANOVA) and independent sample $t$-tests were performed to assess for differences in the mean by publishing year and student authorship, respectively. Chi-square analyses (Fisher exact test for small samples) were used to evaluate differences in categorical variables. Linear data trends were examined by assessing the goodness of fit model based on the means of $\mathrm{H}_{\mathrm{i}}$ scores presented and reported as the value of $\mathrm{R}^{2}$ (range $0-1$ ). A p-value of $<0.05$ was considered statistically significant for all analyses. All statistical computations were performed on SAS 9.3 software (SAS Institute, Cary, NC).

\section{Results}

A total of 701 articles were published in JAMA Internal Medicine, stratified as 246, 248, and 207 articles in the 
Table I Descriptive Analyses of Publications from 2010 to 2018 in JAMA Internal Medicine

\begin{tabular}{|c|c|c|c|c|c|c|c|c|}
\hline & \multicolumn{2}{|c|}{ All } & \multicolumn{2}{|c|}{2010} & \multicolumn{2}{|c|}{2014} & \multicolumn{2}{|c|}{2018} \\
\hline Total number of articles & \multicolumn{2}{|c|}{701} & \multicolumn{2}{|c|}{246} & \multicolumn{2}{|c|}{248} & \multicolumn{2}{|c|}{207} \\
\hline Number of all authors & \multicolumn{2}{|c|}{4591} & \multicolumn{2}{|c|}{1643} & \multicolumn{2}{|c|}{1578} & \multicolumn{2}{|c|}{1370} \\
\hline Number of student authors & \multicolumn{2}{|c|}{683} & \multicolumn{2}{|c|}{205} & \multicolumn{2}{|c|}{214} & \multicolumn{2}{|c|}{264} \\
\hline$\%$ of student authors & \multicolumn{2}{|c|}{14.9} & \multicolumn{2}{|c|}{12.5} & \multicolumn{2}{|c|}{13.6} & \multicolumn{2}{|c|}{19.3} \\
\hline $\begin{array}{l}\text { \# Papers with Student } \\
\text { Authors }\end{array}$ & $\mathbf{n}$ & $\% *$ & $\mathbf{n}$ & $\%$ & $\mathbf{n}$ & $\%$ & $\mathbf{n}$ & $\%$ \\
\hline No & 341 & 48.6 & 132 & 53.7 & 122 & 49.2 & 87 & 42.0 \\
\hline Yes & 360 & 51.4 & 114 & 46.3 & 126 & 50.8 & 120 & 58.0 \\
\hline I & 175 & 48.6 & 53 & 46.5 & 71 & 56.4 & 51 & 42.5 \\
\hline 2 & III & 30.8 & 43 & 37.7 & 32 & 25.4 & 36 & 30.0 \\
\hline 3 or more & 74 & 20.6 & 18 & 15.8 & 23 & 18.3 & 33 & 27.5 \\
\hline $\begin{array}{l}\text { \# of first authors as } \\
\text { students }\end{array}$ & 73 & 20.3 & 20 & 17.5 & 23 & 18.3 & 30 & 25.0 \\
\hline \# of Authors per Paper & $\mathbf{n}$ & $\%$ & $\mathbf{n}$ & $\%$ & $\mathbf{n}$ & $\%$ & $\mathbf{n}$ & $\%$ \\
\hline I to 5 & 335 & 47.8 & 114 & 46.3 & 130 & 52.4 & 91 & 44.0 \\
\hline 6 to 10 & 285 & 40.7 & 105 & 42.7 & 88 & 35.5 & 92 & 44.4 \\
\hline 11 to 15 & 54 & 7.7 & 18 & 7.3 & 22 & 8.9 & 14 & 6.8 \\
\hline 16 or more & 27 & 3.9 & 9 & 3.7 & 8 & 3.2 & 10 & 4.8 \\
\hline
\end{tabular}

Note: *Proportion (\%) over denominator of total articles in that year.

Abbreviation: $n$, number.

years 2010, 2014, and 2018, respectively (Table 1). Of 4591 total authors, 683 (14.9\%) were classified as student authors. The percentage of student authorship was seen to increase over time, where the percentage of authors identified as students rose from $12.5 \%$ in 2010 to $13.6 \%$ in 2014 and $19.3 \%$ in 2018 .

Approximately $46.3 \%$ of articles included at least one student author in 2010, compared to $58.0 \%$ in 2018 . Figure 1 shows the overall number of publications with at least one student author over time $\left(\mathrm{R}^{2}=0.9825\right)$. Of the papers with student author(s), the majority of these papers (mean 79.4\%) had between one and two student authors, with the rest of the papers including more than two student authors (Table 1). The percentage of students as first authors also increased over time, rising from $17.5 \%$ in 2010 to $25.0 \%$ by 2018 .

$\mathrm{H}_{\mathrm{i}}$ for CA with and without SA involvement was found to be similar across both groups (nSA: 30.2 , vs SA: 32.1, $P=0.371$, Table 2). Year-specific $\mathrm{H}_{\mathrm{i}}$ scores seemed slightly higher for SA as compared to nSA, though the results were not statistically significant ( $P>0.05$ ). (Figure 2$)$. In looking at the number of publications stratified by the geographic location of CA, the majority of articles (540/701) originated from the US, followed by Europe $(n=95)$ and Canada ( $\mathrm{n}=32$, Table 3 ). Of the publications arising from the United States, approximately half of the papers came from the Northeast, with smaller proportions from the South and West. Interestingly, regardless of geographic region stratification, at least half of the US publications (range $50.3-58.1 \%, P=0.149$ ) included at least one student author in their author line.

Europe had the second-highest number of articles published overall, though the rates for student authorship were not as high as those from the US. In other words, approximately $37.9 \%$ of papers published in Europe had at least one student author, compared to a mean of $53.3 \%$ articles published in the US with at least one student author. The rest of the student-authored publications came from CAs located in Canada, China/Hong Kong, and Taiwan, among others.

\section{Discussion}

In most academic medical centers, research stands as an important factor for long-term academic success. ${ }^{34,35}$ Studies have shown that the effort spent on research plays a crucial role in the academic promotions of faculty. ${ }^{36-39}$ For medical education, involving students in 


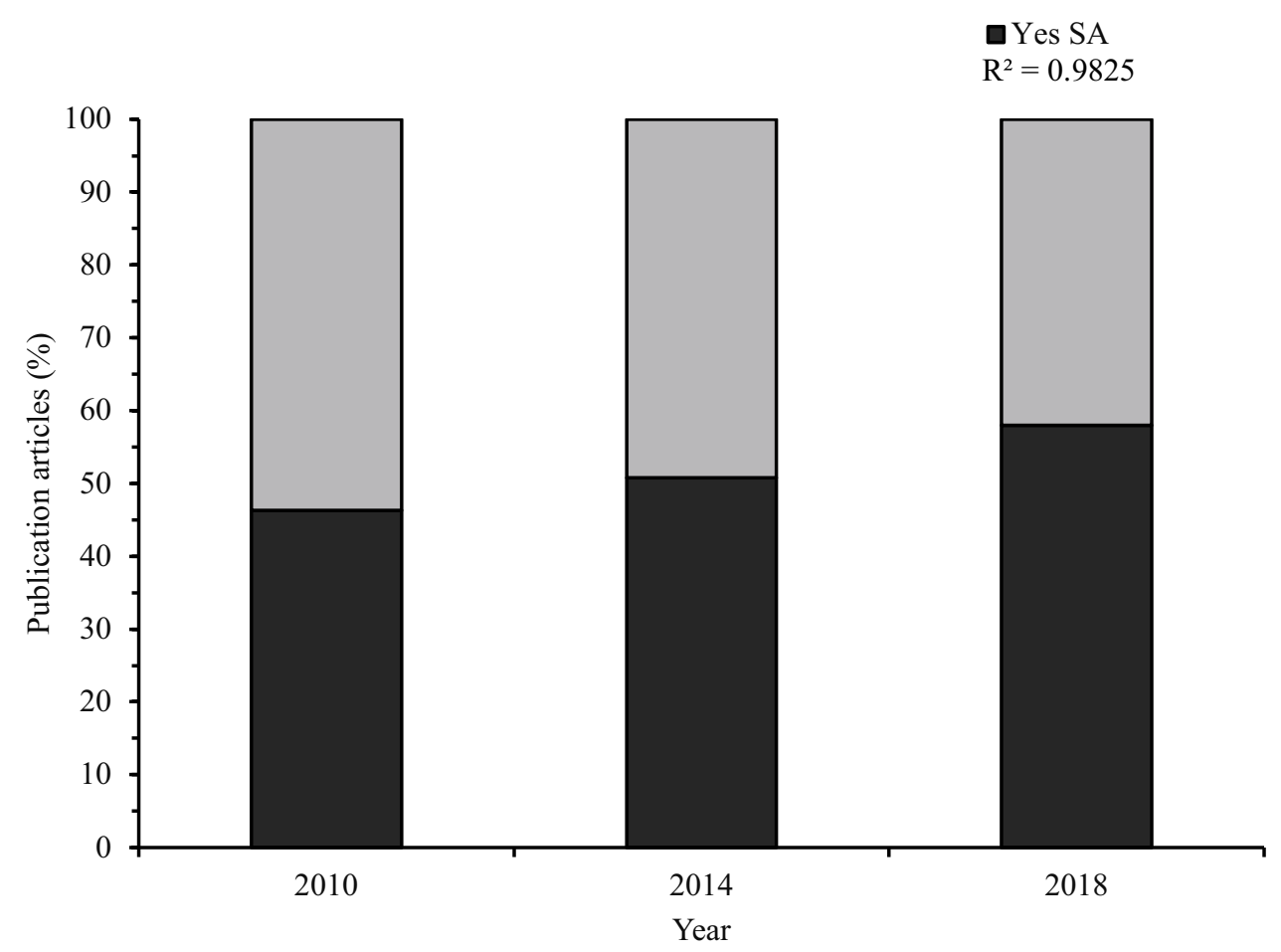

Figure I Distribution of publications $(n=70 I)$ comparing articles with $\geq I$ student authors (SA) versus those with no student authors (no $S A)$ between 2010 to 2018 in JAMA Internal Medicine.

research helps develop professional skills key to continued academic success. ${ }^{40}$ In addition, research has become a constant consideration in NRMP residency applications, with both the number of research projects and the number of published works playing increasingly larger roles. ${ }^{41,42}$

While the role of research has traditionally been strong for applicants matching into number-limiting fields such as surgical sub-specialties, radiology, radiation oncology, and dermatology, applicants for internal medicine have shown a steady increase in research work as well. ${ }^{12,13,43-45}$ Despite the fact that internal medicine continues to be the largest residency by number, data on student authorship rates in medicine and its effect on scholarly impact remain limited. ${ }^{46}$

Our data show an overall increase in student authorship in JAMA Internal Medicine from 2010 to 2018, where the percentage of publications with at least one student author increased from $46.3 \%$ to $58.0 \%$, respectively. The percentage of publications with first student authors had also increased as well, highlighting the trend towards greater student participation in research and suggesting increasing interest in the field of medicine. Our study demonstrates

Table 2 Mean H-Index ( $n=70 I$ ) of Corresponding Authors' (CA) Publications with (SA) or without (nSA) Student Authors Over Time in JAMA Internal Medicine

\begin{tabular}{|c|c|c|c|c|c|c|c|c|c|}
\hline \multirow[t]{2}{*}{ Year } & \multicolumn{4}{|c|}{ No Student Authors } & \multicolumn{4}{|c|}{ Student Authors } & \multirow[t]{2}{*}{$P$} \\
\hline & $\mathbf{n}$ & Mean (SD) & Median & $95 \% \mathrm{Cl}$ & $\mathbf{n}$ & Mean (SD) & Median & $95 \% \mathrm{Cl}$ & \\
\hline All & $34 I$ & $30.2(30.2)$ & 24.0 & $27.0-33.4$ & 360 & $32.1(26.0)$ & 26.5 & $29.4-34.8$ & 0.371 \\
\hline 2010 & 132 & $35.0(29.8)$ & 26.5 & $29.9-40.2$ & 114 & $38.1(25.0)$ & 34.0 & $33.5-42.8$ & 0.383 \\
\hline 2014 & 122 & $32.3(31.7)$ & 26.5 & $26.7-38.0$ & 126 & $34.2(30.6)$ & 25.5 & $28.8-39.6$ & 0.641 \\
\hline 2018 & 87 & $19.8(26.3)$ & 10.0 & |4.2-25.4 & 120 & $24.2(19.0)$ & 19.0 & $20.7-27.6$ & 0.189 \\
\hline
\end{tabular}

Abbreviations: $\mathrm{n}$, number; SD, standard deviation; $\mathrm{Cl}$, confidence interval. 


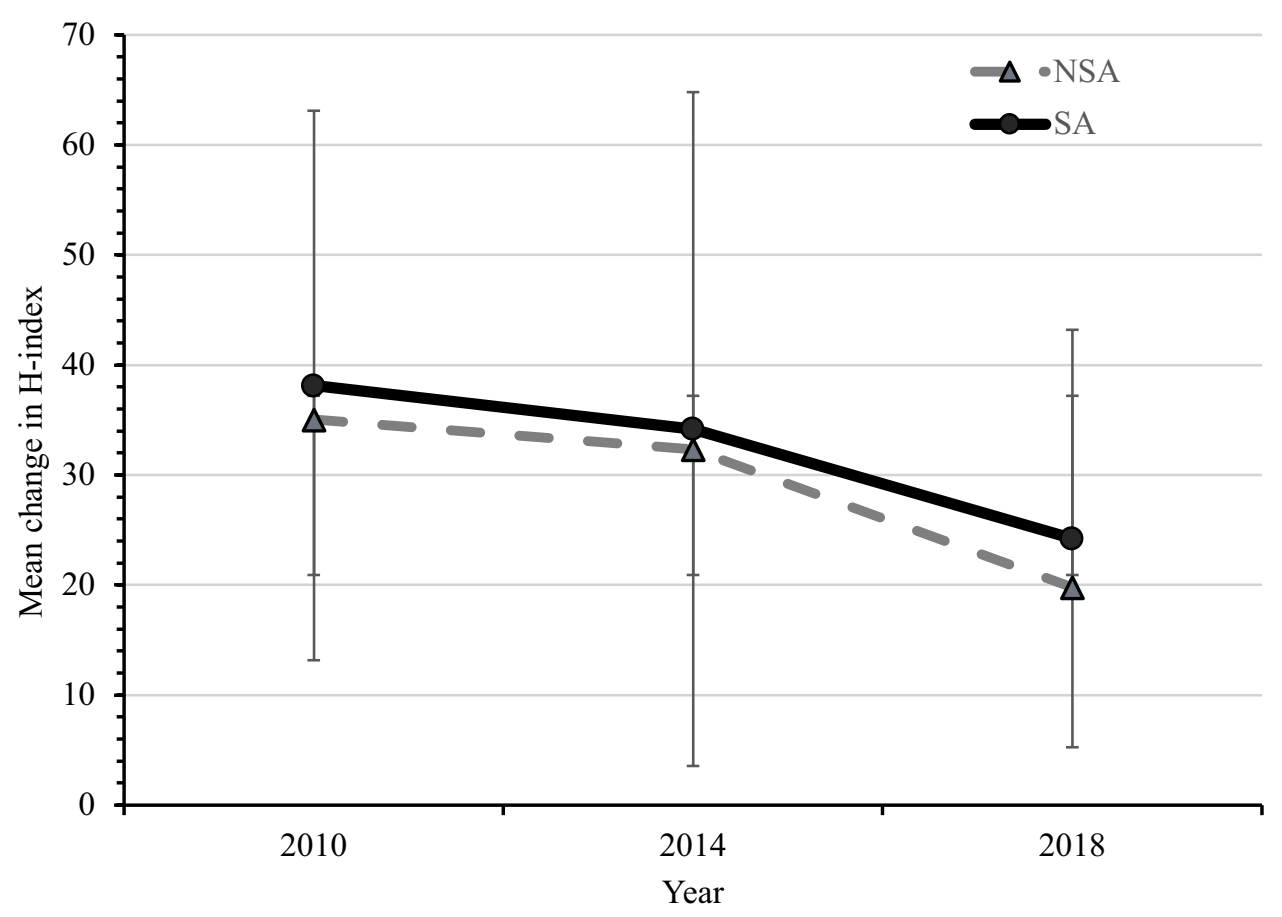

Figure 2 Change in mean $\mathrm{H}$-index and respective standard deviations $(\mathrm{n}=70 \mathrm{I})$ for corresponding authors (CA) in articles published in JAMA Internal Medicine 20I0-20I8 between publications with student authors (SA) and without SA (nSA).

no difference in the average $\mathrm{H}$-indices of $\mathrm{CA}$ between SA and nSA groups.

Generally speaking, authorship trends have slowly increased over time, showing that the number of authors, in general, have increased over the last few decades. In An et al, through a cumulative four urologic journals, authorship counts in original research articles increased by an average of 2.45 per manuscript ( $43.3 \%$ increase) in the last ten years. ${ }^{47}$ Another paper by Filardo et al looked at trends of female first authorship from 1994-2014, to which women representation was significantly higher in the last twenty years. ${ }^{48}$ The gradual increase in overall authorship counts over time may be attributed to increased cooperation and interdisciplinary collaboration. Per An, they noted the need for increased specialization and drawing of experts for more impactful studies, as well as increasing scientific requirements for peer-reviewed publications, as possible reasons for the increasing trend of authorship counts. ${ }^{47}$ As for student authorship, per Munzer et al, sixteen journals were taken in composite review for overall student authorship trends, where student authors represent a small but growing proportion of authors in publications overall, not specific to one journal or our current study. ${ }^{49}$
Furthermore, the relationship between student and mentor has always been closely aligned, with similar end goals but varying reasons for collaboration. For students, motivational factors involve good mentorship, especially in pursuing potential career options, better proficiency in the research process, further understanding of biostatistics applications, and the overall opportunity to publish original work. ${ }^{50}$ For mentors, the literature on mentoring reasons is not as clearly stated. While some studies note overall interest in teaching others about research, other studies noted more personal gain of productivity by involving more people in their research. ${ }^{51}$ In our study, given that it is retrospective and compiling on previously published works, further insight into contributing factors of how student authors became involved in the first place would be limited.

With our study, however, we do show that the employment of student authors does not negatively impact the academic production and thereby the promotional aspirations of faculty.

Regarding measurable outcomes, these can again be derived quantitatively via the $\mathrm{H}$-index, which indirectly notes an author's overall productivity, taking into account the quality of the journal, the measured impact of said research, and the number of research publications. While 
Table 3 Number of Papers with Student Authors: Overall and by Year

\begin{tabular}{|c|c|c|c|c|c|c|c|c|c|c|}
\hline \multirow[t]{2}{*}{ Authorship by Region/Country } & \multirow[t]{2}{*}{ Type of Author } & \multicolumn{2}{|c|}{ All Years } & \multicolumn{2}{|c|}{2010} & \multicolumn{2}{|c|}{2014} & \multicolumn{2}{|c|}{2018} & \multirow[t]{2}{*}{$P$ for Trend } \\
\hline & & \multicolumn{8}{|c|}{ n (Percent) } & \\
\hline \multirow[t]{2}{*}{ Total } & & 701 & & 246 & & 248 & & 207 & & \\
\hline & Student* & 360 & 51.4 & 114 & 46.3 & 126 & 50.8 & 120 & 58 & 0.014 \\
\hline \multirow[t]{2}{*}{ United States } & & 540 & & 161 & & 207 & & 172 & & \\
\hline & Student & 288 & 53.3 & 81 & 50.3 & 107 & 51.7 & 100 & 58.1 & 0.149 \\
\hline \multirow[t]{2}{*}{ District of Columbia } & & 7 & & 2 & & 2 & & 3 & & \\
\hline & Student & 7 & 100 & 2 & 100 & 2 & 100 & 3 & 100 & $\mathrm{~N} / \mathrm{A}$ \\
\hline \multirow[t]{2}{*}{ Northeast } & & 208 & & 60 & & 86 & & 62 & & \\
\hline & Student & 108 & 51.9 & 29 & 48.3 & 47 & 54.7 & 32 & 51.6 & 0.722 \\
\hline \multirow[t]{2}{*}{ Midwest } & All & 76 & & 23 & & 29 & & 24 & & \\
\hline & Student & 42 & 55.3 & 16 & 69.6 & 14 & 48.3 & 12 & 50 & 0.182 \\
\hline \multirow[t]{2}{*}{ South } & & $13 \mid$ & & 40 & & 49 & & 42 & & \\
\hline & Student & 69 & 52.7 & 18 & 45 & 26 & 53.1 & 25 & 59.5 & 0.188 \\
\hline \multirow[t]{2}{*}{ West } & & 118 & & 36 & & 41 & & 41 & & \\
\hline & Student & 62 & 52.5 & 16 & 44.4 & 18 & 43.9 & 28 & 68.3 & 0.032 \\
\hline \multirow[t]{2}{*}{ Canada } & & 32 & & 12 & & 7 & & 13 & & \\
\hline & Student & 21 & 65.6 & 8 & 66.7 & 5 & 71.4 & 8 & 61.5 & 0.782 \\
\hline \multirow[t]{2}{*}{ Europe } & & 95 & & 56 & & 25 & & 14 & & \\
\hline & Student & 36 & 37.9 & 20 & 35.7 & 10 & 40 & 6 & 42.9 & 0.582 \\
\hline \multirow{2}{*}{ Netherlands } & & 18 & & 13 & & 4 & & I & & \\
\hline & Student & 7 & 38.9 & 6 & 46.2 & I & 25 & 0 & 0 & 0.264 \\
\hline \multirow[t]{2}{*}{ France } & & 12 & & 7 & & 3 & & 2 & & \\
\hline & Student & 7 & 58.3 & 3 & 42.9 & 2 & 66.7 & 2 & 100 & 0.139 \\
\hline \multirow[t]{2}{*}{ UK } & & 12 & & 5 & & 3 & & 4 & & \\
\hline & Student & 4 & 33.3 & I & 20 & I & 33.3 & 2 & 50 & 0.344 \\
\hline \multirow[t]{2}{*}{ Germany } & & 9 & & 6 & & 3 & & 0 & & \\
\hline & Student & 3 & 33.3 & I & 16.7 & 2 & 33.3 & 0 & & N/A \\
\hline \multirow[t]{2}{*}{ Denmark } & All & 7 & & 1 & & 4 & & 2 & & \\
\hline & Student & 5 & 71.4 & I & 100 & 3 & 75 & I & 50 & 0.35 \\
\hline \multirow[t]{2}{*}{ Sweden } & & 6 & & 4 & & I & & I & & \\
\hline & Student & 4 & 66.7 & 3 & 75 & I & 100 & 0 & 0 & 0.257 \\
\hline \multirow[t]{2}{*}{ Other** } & & 31 & & 20 & & 7 & & 4 & & \\
\hline & Student & 6 & 19.4 & 5 & 25.0 & 0 & 0 & I & 25.0 & 0.565 \\
\hline Asia & & 23 & & 10 & & 7 & & 6 & & 0.012 \\
\hline & Student & II & 47.8 & 2 & 20 & 4 & 57.1 & 5 & 83.3 & \\
\hline China/HK & & 8 & & 3 & & 3 & & 2 & & \\
\hline & Student & 5 & 62.5 & 0 & 0 & 3 & 100 & 2 & 100 & 0.014 \\
\hline Taiwan & All & 6 & & 3 & & 2 & & 1 & & \\
\hline & Student & 2 & 33.3 & 0 & 0 & I & 50 & 1 & 100 & 0.053 \\
\hline
\end{tabular}

(Continued) 
Table 3 (Continued).

\begin{tabular}{|l|l|l|l|l|l|l|l|l|l|l|}
\hline Authorship by Region/Country & Type of Author & \multicolumn{2}{l|}{ All Years } & \multicolumn{2}{l|}{2010} & \multicolumn{2}{l|}{2014} & \multicolumn{2}{l|}{2018} & \multicolumn{2}{l|}{$\boldsymbol{P}$ for Trend } \\
\hline \multirow{2}{*}{ Other*** } & All & 9 & & 4 & & 2 & & 3 & \\
& Student & 4 & 44.4 & 2 & 50 & 0 & 0 & 2 & 66.7 & 0.733 \\
\hline Australia/NZ & All & II & & 7 & & 2 & & 2 & & \\
& Student & 4 & 36.4 & 3 & 42.9 & 0 & 0 & 1 & 50 & 0.884 \\
\hline
\end{tabular}

Notes: *Student denotes that at least one student author was included in the publication's author line. **Other Europe: Belgium 2, Finland 4, Ireland I, Israel 3, Italy 8, Norway I, Portugal I, Spain 3, Switzerland 6, Turkey 2, = 31 total. ***Other Asia: India 3, Japan 2, Korea I, Singapore 3, = 9 total.

in our study, the H-index between papers with student authors and without student authors was not statistically significant $(\mathrm{p}=0.371)$; however this does not exclude the potential qualitative outcomes of having student authors involved in research studies. Through an integrated mixed-methods systematic review and meta-analyses, Amgad et al found that medical students who participated in the research were associated with improved short and long-term scientific productivity, more informed career choices, and improved knowledge and interest in research. ${ }^{52}$ Similar findings were noted in Cheung et al, as well as Laidlaw, both of which also commented on developing lifelong research skills beneficial in honing on evidence-based medicine in future years. ${ }^{53,54}$ Whereas student-reported barriers to research often highlight a perceived lack of interest from potential mentors, our data suggests a potentially mutually beneficial relationship. Previous studies looking at the correlation between medical student involvement and faculty scholarly productivity have similarly shown either a beneficial or neutral relationship, corresponding to our current findings. ${ }^{55,56}$ Whereas faculty can offer mentorship and research expertise, students have the added benefit of time to contribute and, in return, become involved in research projects to stimulate their careers. ${ }^{57,58}$ Indeed, it is likely that the addition of student authors adds proof of academic mentorship, which is also often employed as a measure for faculty promotion. ${ }^{58-60}$

There are several limitations to our study. This study is retrospective and, as such, may suffer from selection bias. Specifically, given that the papers included in our research were preselected for publications, there would be selection bias as to which studies were considered in our study. While $\mathrm{H}_{\mathrm{i}}$ scores are not a reliable surrogate for scholarly impact, they remain widely used to identify research. The actual number of student authors may vary from our numbers. For instance, we identified all non-doctorate authors as student authors, which may overestimate the number. On the opposite end, the time interval between research and publication may lead to graduate degrees for those who performed their research while students, underestimating the number. However, since our comparisons are consistent over time, we believe our interpretation of the data is appropriate. Students may seek research mentors with higher $\mathrm{H}_{\mathrm{i}}$ scores, artificially elevating scores of CAs with SA. Finally, this information is collected from a single leading journal of internal medicine; however, as the journal represents a broad range of medicine disciplines with a high impact factor of 20.8, we feel that JAMA Internal Medicine is an appropriate journal to best evaluate student authorship in internal medicine. Further studies on understanding the underlying decision-making in choosing research mentors may help identify patterns of student authorship.

\section{Conclusion}

The rate of student authorship in JAMA Internal Medicine increased between 2010 and 2018. Student participation in research does not negatively impact author productivity, and may in fact benefit faculty promotion when mentorship is evaluated. This mutually beneficial relationship between the corresponding author and students should encourage more faculty to seek out student mentees.

\section{Author Contributions}

All authors made substantial contributions to conception and design, acquisition of data, or analysis and interpretation of data; took part in drafting the article or revising it critically for important intellectual content; agreed to submit to the current journal; gave final approval of the version to be published; and agree to be accountable for all aspects of the work. 


\section{Disclosure}

The authors have stated that they have no conflicts of interest.

\section{References}

1. Beasley BW, Wright SM. Looking forward to promotion: characteristics of participants in the prospective study of promotion in academia. J Gen Intern Med. 2003;18(9):705-710. doi:10.1046/ j.1525-1497.2003.20639.x

2. Aggarwal R, Gogtay N, Kumar R, et al. The revised guidelines of the Medical Council of India for academic promotions: need for a rethink. Indian $J$ Gastroenterol. 2016;35(1):3-6. doi:10.1007/ s12664-015-0617-9

3. Beasley BW, Simon SD, Wright SM. A time to be promoted: the prospective study of promotion in academia. J Gen Intern Med. 2006;21(2):123-129. doi:10.1111/j.1525-1497.2005.00297.x

4. Amgad M, Man Kin Tsui M, Liptrott SJ, Shash E. Medical student research: an integrated mixed-methods systematic review and meta-analysis. PLoS One. 2015;10(6):e0127470.

5. Weaver AN, McCaw TR, Fifolt M, et al. Impact of elective versus required medical school research experiences on career outcomes. J Investig Med. 2017;65(5):942-948. doi:10.1136/jim-2016-000352

6. Cluver J, Book S, Brady K, et al. Engaging medical students in research: reaching out to the next generation of physician-scientists. Acad Psychiatry. 2014;38(3):345-349. doi:10.1007/s40596-0140097-8

7. Kaskas NM, Ballard DH, Weisman JA, Vanchiere JA. Medical student journals: teaching the peer-review process and promoting academic mentorship. J La State Med Soc. 2016;168(5):166.

8. Langhammer CG, Garg K, Neubauer JA, et al. Medical student research exposure via a series of modular research programs. $J \quad$ Investig Med. 2009;57(1):11-17. doi:10.2310/JIM.0b 013e3181946fec

9. Vereijken MWC, van der Rijst RM, van Driel JH, Dekker FW. Student learning outcomes, perceptions and beliefs in the context of strengthening research integration into the first year of medical school. Adv Health Sci Educ Theory Pract. 2018;23(2):371-385. doi:10.1007/s10459-017-9803-0

10. Pathipati AS, Taleghani N. Research in medical school: a survey evaluating why medical students take research years. Cureus. 2016;8(8):e741. doi:10.7759/cureus.741

11. Conroy MB, Shaffiey S, Jones S, et al. Scholarly research projects benefit medical students' research productivity and residency choice: outcomes from the University of Pittsburgh School of Medicine. Acad Med. 2018;93(11):1727-1731. doi:10.1097/ ACM.0000000000002328

12. National Resident Matching Program. Charting outcomes in the match: characteristics of US allopathic seniors who matched to their preferred specialty in the 2018 main residency match. Washington DC: National Resident Matching Program; 2018. Available from: http://www.nrmp.org/main-residency-match-data/. Accessed May 18, 2020.

13. National Resident Matching Program. Charting outcomes in the match: characteristics of applicants who matched to their preferred specialty in the 2009 main residency match. Washington DC: National Resident Matching Program; 2009. Available from: http:// www.nrmp.org/report-archives/. Accessed May 18, 2020.

14. Young BK, Cai F, Tandon VJ, et al. Promoting medical student research productivity: the student perspective. R I Med J. 2014;97 (6):50-52.

15. Ashcroft J, Yousefpour C. Medical student research: it is necessary and beneficial! Postgrad Med J. 2018;94(1115):539. doi:10.1136/ postgradmedj-2018-135954
16. Chang Y, Ramnanan CJ. A review of literature on medical students and scholarly research: experiences, attitude, and outcomes. Acad Med. 2015;90(8):1162-1173. doi:10.1097/ACM.0000000000000702

17. Ha TC, $\mathrm{Ng} \mathrm{S}$, Chen $\mathrm{C}$, et al. Inclination towards research and the pursuit of a research career among US medical students: an international cohort study. BMC Med Educ. 2018;18(1):86. doi:10.1186/ s12909-018-1202-6

18. Ringsted C. How does research on motor skills translate into clinical skills learning? Med Educ. 2009;44(1):11-13. doi:10.1111/j.13652923.2009.03563.x

19. Siemens DR, Punnen S, Wong J, Kanji N. A survey on the attitudes towards research in medical school. BMC Med Educ. 2010;10(1):4. doi:10.1186/1472-6920-10-4

20. Funston G, Piper RJ, Connell C, et al. Medical student perceptions of research and research-oriented careers: an international questionnaire study. Med Teach. 2016;38(10):1041-1048. doi:10.3109/ 0142159X.2016.1150981

21. Gouda P, O' Flynn S, Cantillon P. Desires versus reality of medical and health science summer student research opportunities. Ir J Med Sci. 2018;187(3):817-820. doi:10.1007/s11845-017-1705-x

22. Russell CD, Lawson McLean A, MacGregor KE, et al. Perceived barriers to research in undergraduate medicine. Med Teach. 2012;34 (9):777-778. doi:10.3109/0142159X.2012.700143

23. Hirsch JE. An index to quantify an individual's scientific research output. PNAS. 2005;102(46):16569-16572. doi:10.1073/pnas.0507655102

24. Hirsch JE. Does the H index have predictive power? PNAS. 2007;104 (49):19193-19198. doi:10.1073/pnas.0707962104

25. Dinis-Oliveira RJ. The H-index in life and health sciences: advantages, drawbacks, and challenging opportunities. Curr Drug Res Rev. 2019;11(2):82-84. doi:10.2174/258997751102191111141801

26. Jialal I, Schreiber WE, Giustini DM. H-index and academic medicine. Am J Clin Pathol. 2019;151(6):648-649. doi:10.1093/ ajcp/aqz037

27. Nowak JK, Lubarski K, Kowalik LM, Walkowiak J. H-index in medicine is driven by original research. Croat Med J. 2018;59 (1):25-32. doi:10.3325/cmj.2018.59.25

28. Patel VM, Ashrafian H, Bornmann L, et al. Enhancing the h-index for the objective assessment of healthcare researcher performance and impact. J R Soc Med. 2013;106(1):19-29. doi:10.1258/jrsm.2012.120253

29. Miro O, Burbano P, Graham CA, et al. Analysis of h-index and other bibliometric markers of productivity and repercussion of a selected sample of worldwide emergency medicine researchers. Emerg Med J. 2017;34(3):175-181. doi:10.1136/emermed-2016-205893

30. Ashfaq A, Kalagara R, Wasif N. H-index and academic rank in general surgery and surgical specialties in the United States. $J$ Surg Res. 2018;229:108-113. doi:10.1016/j.jss.2018.03.059

31. Paracha M, Hirsch AE, Tseng JF, et al. Scholarly impact of student authorship on surgical research. Am J Surg. 2019;217(1):175-179. doi:10.1016/j.amjsurg.2018.07.045

32. Paracha M, Kim KN, Qureshi MM, et al. Scholarly impact of student participation in radiation oncology research. Int J Radiat Oncol Biol Phys. 2018;101(4):779-783. doi:10.1016/j.ijrobp.2018.02.154

33. Scopus. Available from: https://www.scopus.com/freelookup/form/ author.uri https://www.scopus.com/freelookup/form/author.uri. AccessedMay 18, 2020.

34. Bobian MR, Shah N, Svider PF, et al. Does formal research training lead to academic success in otolaryngology? Laryngoscope. 2017;127 (1):E15-21. doi:10.1002/lary.26189

35. International Working Party. Academic medicine: the evidence base. BMJ. 2004;329(7469):789-792. doi:10.1136/bmj.329.7469.789

36. Farrokhyar F, Bianco D, Dao D, et al. Impact of research investment on scientific productivity of junior researchers. Transl Behav Med. 2016;6(4):659-668. doi:10.1007/s13142-015-0361-9

37. Chung SW, Clifton JS, Rowe AJ, et al. Strategic faculty recruitment increases research productivity within an academic university division. Can J Surg. 2009;52(5):401-406. 
38. Buckley LM, Sanders K, Shih M, Hamptom CL. Attitudes of clinical faculty about career progress, career success and recognition, and commitment to academic medicine. Results of a survey. Arch Intern Med. 2000;160(17):2625-2629. doi:10.1001/archinte.160.17.2625

39. MacMaster FP, Swansburg R, Rittenbach K. Academic productivity in psychiatry: benchmarks for the H-index. Acad Psychiatry. 2017;41 (4):452-454. doi:10.1007/s40596-016-0656-2

40. Laidlaw A, Aiton J, Struthers J, Guild S. Developing research skills in medical students: AMEE Guide No 69. Med Teach. 2012;34(9): e754-71. doi:10.3109/0142159X.2012.704438

41. Katzung KG, Ankel F, Clark M, et al. What do program directors look for in an applicant? J Emerg Med. 2019;56(5):e95-101. doi:10.1016/j.jemermed.2019.01.010

42. Imam Z, Cappell MS. Increased average number of medical publications per interviewee from 2009 to 2018: a study of 100 interviewees to an academic gastroenterology fellowship program. BMC Med Educ. 2019;19(1):402. doi:10.1186/s12909-019-1841-2

43. Wadhwa H, Shah SS, Shan J, et al. The neurosurgery applicant's "arms race": analysis of medical student publication in the neurosurgery residency match. J Neurosurg. 2019;1:1-9.

44. Pretorius ES, Solomon JA, Stribling C. Medical student attitudes toward inclusion of a research year within diagnostic radiology residency: a survey of students participating in the 2002 NRMP Match. national resident matching program. Acad Radiol. 2003;10 (1):77-82. doi:10.1016/S1076-6332(03)80792-4

45. Prasad V, Rho J, Selvaraj S, et al. Publication trends among internal medicine residents and graduates. Am J Med. 2012;125(9):939-944.

46. Vassallo E Internal medicine residency match the largest in history, reflecting essential role of internists. American College of Physicians; 2020. Available from: https://www.acponline.org/acp-newsroom/inter nal-medicine-residency-match-the-largest-in-history-reflectingessential-role-of-internists. Accessed May 18, 2020.

47. An JY, Baiocco JA, Rais-Bahrami S. Trends in the authorship of peer reviewed publications in urology literature. Urol Pract. 2018;5 (3):233-239. doi:10.1016/j.urpr.2017.03.008

48. Filardo G, Graca B, Sass DM, et al. Trends and comparison of female first authorship in high impact medical journals: observational study (1994-2014). BMJ. 2016;352:i847. doi:10.1136/bmj.i847

49. Munzer BW, Griffith M, Townsend WA, Burk-Rafel J. Medical student- and resident-authored publications in academic medicine from 2002 to 2016: a growing trend and its implications. Acad Med. 2019;94(3):404-411. doi:10.1097/ACM.0000000000002466
50. Bonilla-Escobar FJ, Bonilla-Velez J, Tobon-Garcia D, Angel-Isaza AM. Medical student researchers in Colombia and associated factors with publication: a cross-sectional study. BMC Med Educ. 2017;17 (1):254. doi:10.1186/s12909-017-1087-9

51. Partido BB, Chartier EA, Heminger B. Experiences and attitudes of dental hygiene faculty regarding the mentorship of undergraduate student research. $J$ Dent Educ. 2020;84(11):1202-1209. doi:10.1002/jdd. 12290

52. Amgad M, Tsui MMK, Liptrott SJ, Shash E. Medical student research: an integrated mixed-methods systematic review and meta-analysis. PLoS One. 2015;10(6):e0127470. doi:10.1371/journal.pone. 0127470

53. Cheung BMY. Medical student research: is it necessary and beneficial? Postgrad Med J. 2018;94(1112):317. doi:10.1136/postgradmedj-2018-135834

54. Laidlaw A, Aiton J, Struthers J, Guild S. Developing research skills in medical students: AMEE Guide No 69. Med Teach. 2012;34(9): e754-71.

55. Svider PF, Husain Q, Mauro KM, et al. Impact of mentoring medical students on scholarly productivity. Int Forum Allergy Rhinol. 2014;4 (2):138-142. doi:10.1002/alr.21247

56. Sambunjak D, Straus SE, Marusic A. Mentoring in academic medicine: a systematic review. JAMA. 2006;296(9):1103-1115. doi:10.1001/jama.296.9.1103

57. Jacobs CD, Cross PC. The value of medical student research: the experience at Stanford University School of Medicine. Med Educ. 1995;29(5):342-346. doi:10.1111/j.1365-2923.1995.tb00023.x

58. Al-Busaidi IS, Tarr GP. Dissemination of results from medical student public health research training and factors associated with publication. Postgrad Med J. 2018;94(1112):330-334. doi:10.1136/ postgradmedj-2017-135361

59. Nimmons D, Giny S, Rosenthal J. Medical student mentoring programs: current insights. Adv Med Educ Pract. 2019;10:113-123. doi:10.2147/AMEP.S154974

60. Fernandez A, Chen V, Quan J, et al. Evaluation of a medical student research and career development program to increase diversity in academic medicine. Acad Med. 2019;94(8):1220-1228. doi:10.1097/ ACM.0000000000002760
Advances in Medical Education and Practice

\section{Publish your work in this journal}

Advances in Medical Education and Practice is an international, peerreviewed, open access journal that aims to present and publish research on Medical Education covering medical, dental, nursing and allied health care professional education. The journal covers undergraduate education, postgraduate training and continuing medical education
Dovepress

including emerging trends and innovative models linking education, research, and health care services. The manuscript management system is completely online and includes a very quick and fair peer-review system. Visit http://www.dovepress.com/testimonials.php to read real quotes from published authors. 